\title{
Management of functional communication, swallowing, cough and related disorders: consensus recommendations for speech and language therapy
}

\author{
Janet Baker, ${ }^{1,2}$ Caroline Barnett, ${ }^{3}$ Lesley Cavalli, ${ }^{4,5}$ Maria Dietrich, ${ }^{6}$ Lorna Dixon, ${ }^{7}$ \\ Joseph R Duffy, ${ }^{8}$ Annie Elias, ${ }^{9}$ Diane E Fraser, ${ }^{10}$ Jennifer L Freeburn, ${ }_{14}$ \\ Catherine Gregory, ${ }^{2}$ Kirsty McKenzie, ${ }^{12}$ Nick Miller, ${ }^{13}$ Jo Patterson, ${ }_{1}^{14}$ Carole Roth, ${ }^{15}$ \\ Nelson Roy, ${ }^{16,17}$ Jennifer Short, ${ }^{18}$ Rene Utianski $10,{ }^{19,20}$ Miriam van Mersbergen, ${ }^{21}$ \\ Anne Vertigan, ${ }^{22,23}$ Alan Carson, ${ }^{24}$ Jon Stone $\left(10,{ }^{24}\right.$ Laura McWhirter (1) ${ }^{24}$
}

\begin{abstract}
- Additional online supplemental material is published online only. To view, please visit the journal online (http://dx.doi.org/10.1136/ jnnp-2021-326767).

For numbered affiliations see end of article.
\end{abstract}

\section{Correspondence to}

Dr Laura McWhirter, Centre for Clinical Brain Sciences, The University of Edinburgh, Edinburgh, Edinburgh, UK laura.mcwhirter@ed.ac.uk

Received 1 April 2021 Accepted 25 May 2021 Published Online First 1 July 2021

\section{SLinked}

- http://dx.doi.org/10.1136/ jnnp-2021-327213

\section{Check for updates}

(C) Author(s) (or their employer(s)) 2021. No commercial re-use. See rights and permissions. Published by BMJ.

To cite: Baker J, Barnett C Cavalli L, et al. J Neurol Neurosurg Psychiatry 2021:92:1112-1125.

\section{ABSTRACT}

Communication problems (eg, dysphonia, dysfluency and language and articulation disorders), swallowing disorders (dysphagia and globus), cough and upper airway symptoms, resulting from functional neurological disorder (FND), are commonly encountered by speech and language professionals. However, there are few descriptions in the literature of the most effective practical management approaches. This consensus document aims to provide recommendations for assessment and intervention that are relevant to both adults and young people. An international panel of speech and language professionals with expertise in FND were approached to take part. Participants responded individually by email to a set of key questions regarding best practice for assessment and interventions. Next, a video conference was held in which participants discussed and debated the answers to these key questions, aiming to achieve consensus on each issue. Drafts of the collated consensus recommendations were circulated until consensus was achieved. FND should be diagnosed on the basis of positive clinical features. Speech and language therapy for FND should address illness beliefs, self-directed attention and abnormal movement patterns through a process of education, symptomatic treatment and cognitive behavioural therapy within a supportive therapeutic environment. We provide specific examples of these strategies for different symptoms. Speech and language professionals have a key role in the management of people with communication and related symptoms of FND. It is intended that these expert recommendations serve as both a practical toolkit and a starting point for further research into evidence-based treatments.

\section{INTRODUCTION}

The pivotal role of the speech and language professional has been long established in the management of a range of disorders of communication, swallowing and cough.

There is a strong evidence base for the treatment of the aforementioned disorders occurring during childhood development, in association with structural anomalies, and as the result of neurological disease or injury. In contrast, there have been comparatively few intervention and outcome studies for individuals with functional communication, swallowing and cough disorders; while there is some evidence for the assessment and treatment of functional dysphonia and dysphagia, other symptoms have received very little systematic research attention.

In functional neurological disorder (FND), neurological symptoms are experienced which are genuine, and usually associated with distress and disability, as a result of potentially reversible changes in function and not as a result of disease, damage or structural abnormality. ${ }^{1}$ FND is a common cause of neurological symptoms, present in around one in six patients presenting to neurology outpatient clinics. ${ }^{2}$ Crucially, FND is diagnosed on the basis of positive clinical features of internal inconsistency, and not by exclusion of structural damage or disease. ${ }^{1}$ FND is also described in children and young people, ${ }^{3}$ in whom successful outcomes have been reported by speech and language professionals.

Although many speech and language professionals will have assessed or treated people with functional dysphonia, they may also be asked to assist with differential diagnosis or provide treatment of a much wider range of functional communication, swallowing and cough disorders, in isolation or in combination with other symptoms of FND. This is an area in which some and perhaps many speech and language professionals have felt unsure or underprepared when asked to provide treatment. ${ }^{4}$ And yet these disorders are not rare: review of referrals to one large US speech pathology department over a 3-year period found that (excluding functional dysphonia) $3 \%$ of patients with acquired communication disorders had functional disorders. ${ }^{5}$

These consensus recommendations for assessment and intervention draw on published evidence where available. However, in areas where empirical evidence is sparse, the approaches recommended here represent those the authors have found useful in their own clinical practices.

We hope that these recommendations will assist practitioners in their practical management of these disorders, and support future research towards evidence-based treatments. 
This is a shortened version of our full recommendations (see online supplemental file 1) which contain more information about diagnosis and further detail of management of functional foreign accent syndrome (FAS) and related disorders, globus/ functional dysphagia and laryngeal hypersensitivity syndrome/ functional cough. We would like to direct the reader to these full recommendations (see online supplemental file 1 ).

\section{METHOD}

\section{Consensus process}

A modified Delphi approach was used. Speech and language professionals from different countries with extensive experience with functional communication, swallowing or upper airway-related symptoms (including cough and/or breathing) were identified from an initial review of the literature and subsequent snowball recruitment from professional networks, and were invited to respond to a series of questions relating to their recommendations for assessment and treatment. This was followed by two videoconference discussions, after which a draft of each subsequent document was circulated three times until consensus was reached. The aims and methods were similar to those used to develop published recommendations for occupational therapy and physiotherapy in FND; it is intended that this document complements these publications. ${ }^{67}$

\section{Participants}

The group included 18 speech and language professionals (speech and language therapists/speech-language pathologists; nine based in the UK, five in the USA, one in Germany (German and USA trained) and three in Australia) with clinical experience of treating patients with FND. Participants had between 6 and 46 years of postgraduate experience. The group also included UK representatives from neuropsychiatry $(n=2)$ and neurology $(\mathrm{n}=1)$, supporting a multidisciplinary approach.

\section{Terminology}

Historically, FNDs have had many names including conversion disorder, psychogenic, psychosomatic, somatoform, medically unexplained or functional; these terms reflect differing behavioural, physical and psychological perspectives. There is now reasonable consensus among neurologists and psychiatrists that the term functional is the most appropriate diagnostic term, primarily to emphasise a disorder of function with aetiological neutrality, when referring to specific symptoms (eg, functional dystonia, functional tremor, functional blindness). FND symptom as defined by the DSM-5 (2013) is the umbrella term for these disorders which lie at the interface between neurology and psychiatry. Diagnosis of FND Symptom in DSM-V requires the presence of one or more symptom of altered voluntary motor or sensory function, which is incompatible with or not better explained by other recognised neurological or medical conditions, and which causes clinically significant distress or impairment. Each symptom type may be specified, that is, 'With swallowing symptoms' or 'With speech symptoms'. Speech and communication symptoms may occur in isolation, or alongside a range of other functional neurological symptoms.

There continues to be confusion about the most appropriate terminology for disorders of communication, swallowing and cough in the absence of structural or neurological pathology. Difficulties in reconciling terms for these symptoms can undermine efforts to define clinical phenotypes, to collate data and to develop evidence-based treatments. ${ }^{8-10}$
Box 1 Functional communication, swallowing and cough disorders-conceptual understanding

Functional communication, swallowing and other upper airwayrelated (eg, cough and breathing) disorders occur when there is a loss of voluntary control or altered sense of self-agency (the subjective experience of controlling one's own actions ${ }^{24}$ ) over the initiation, inhibition and maintenance of the functions involved in speech, voice, language, swallowing, breathing or cough. As a result, there often is inconsistency between voluntary functions, which become inaccessible or excessively effortful, and automatic functions, which are usually preserved.

The symptoms of functional disorders are genuinely experienced and involuntary. A range of biological, psychological and social predisposing, precipitating and perpetuating factors (table 1) are recognised.

This document aims to focus on the elements of effective treatment, rather than on these complex issues of terminology and definition. In the interests of consistency, therefore, the term functional will be used throughout this document to refer to these disorders of communication, swallowing and cough. An inclusive approach has been taken in including symptoms (eg, globus and dysphagia) which may fall between definitions of FND and functional somatic symptoms but which are commonly encountered in the clinical practice.

\section{Conceptual understanding}

Some reviews have examined psychosocial risk factors in functional communication and related disorders. ${ }^{5}$ 11-18 However, symptoms do not always develop after major adverse life events, or in the context of clinically diagnosable psychological distress or psychiatric comorbidity, and the absence of adversity or distress should not be taken as evidence that the disorder is not functional. ${ }^{12} 19$ In common with FND in general, symptoms often develop instead in the context of injury or illness, for example, upper respiratory tract infection, voice overuse, injury to the face, mouth, oropharynx or larynx; traumatic head injury.

This group's consensus on the conceptual understanding of the diagnosis of communication and related FND symptoms (box 1) is informed by current and widely accepted explanatory models for FND. ${ }^{120-24}$

\section{The role of the speech and language professional}

In the full version of this document (see online supplemental file 1) we conclude that the existing skillset and practice environment of most speech and language professionals allows for a major contribution to the diagnosis and effective treatment of most functional communication, swallowing and cough disorders, including as part of the multidisciplinary team.

\section{Initial assessment}

Aims of the initial assessment include information-gathering and preliminary diagnostic formulation, and rapport building; attention to additional elements can be helpful in establishing illness beliefs and expectations which may be important in maintenance of symptoms, the conduct of therapy, and response to treatment (box 2). Anecdotal evidence suggests that many patients with FND only attend for one session, similar to findings for psychotherapy, ${ }^{25}$ so it is crucial that the first session is a positive experience. $^{726-28}$ 
Box 2 Important elements of the history to consider during initial assessment

1. How and when did the symptom(s) begin, and what does the person understand about the possible cause of the symptoms?

2. Do symptoms come and go, or are they constant? Are there any exacerbating or relieving factors? Have there been any periods when the symptoms have disappeared completely?

3. What has the patient been told about the symptoms by other health professionals? What has been the outcome of any previous treatments for the same symptoms?

4. What is the impact of the symptoms on daily life, work, and relationships? The extended psychosocial interview developed by Butcher et $a l^{13}$ may be helpful in this regard.

Psychosocial assessment often provides an understanding of the life events, relationships, and personality traits that may be relevant to the symptoms. Gentle enquiry about recent stresses or significant events is appropriate, as part of an exploration of the risk factors described in table 1 . However, while some patients are interested and may benefit from exploring the possible relationship between their experience of psychosocial trauma or distress and their symptoms, others prefer not to do so. It is important that patients are made to feel comfortable discussing such issues, but it is also important not to probe injudiciously if a history of trauma is not forthcoming; it is possible that there has been no relevant psychological trauma or adverse life events and repeated uninvited questioning about trauma can undermine the therapeutic relationship. It is also important that speech and language professionals are aware of available local resources with appropriate levels of expertise to address suspected or certain significant psychological/psychiatric/ psychosocial needs that may need to be addressed prior to or concurrently with symptomatic treatment of communication or swallowing symptoms.

\section{Diagnosis of FND}

FND should not be a diagnosis based on the exclusion of disease. $^{127}$ In line with FND in general, a range of positive clinical features of functional communication, swallowing and cough disorders are now recognised which support a positive diagnosis of FND. General features are outlined in table 2; examples of specific symptom profiles are described in the relevant sections below. These features may be observed during history taking, during the standard motor speech examination, or may be observable in the person's social utterances and activities, specific speech or swallowing tasks or conversational speech.

Although diagnosis of a functional disorder can generally be made on the basis of positive features, comorbid structural pathology should be excluded early in the diagnostic process (with appropriate investigations, when necessary), even when a functional diagnosis seems likely. Importantly, the presence of 'structural' pathology does not exclude an FND diagnosis, which can be comorbid with structural or neurological disease, possibly representing 'functional overlay', and can be identified on the basis of positive clinical features. In such cases the speech and language professional plays an important role in the process of differential diagnosis and communicating to the patient and other clinicians in the multidisciplinary team which elements of the presentation are the result of structural damage or disease and which have a functional basis.

Table 1 A model of predisposing, precipitating and perpetuating risk factors for functional communication, swallowing and cough disorders ${ }^{713143448}$

\begin{tabular}{|c|c|c|c|}
\hline Factors: & Biological & Psychological & Social \\
\hline Predisposing vulnerabilities & $\begin{array}{l}\text { Genetic factors. } \\
\text { Previous functional symptoms and disorders. } \\
\text { Pre-existing medical illness, especially affecting } \\
\text { communication, for example, traumatic brain injury. } \\
\text { Biological vulnerabilities in nervous system, lower/ } \\
\text { upper respiratory system, head and neck. }\end{array}$ & $\begin{array}{l}\text { Personality traits (neuroticism, low social } \\
\text { potency, stress reactivity, emotional inhibition, } \\
\text { low self-esteem, perfectionism). } \\
\text { Interpersonal difficulties. } \\
\text { Suggestibility. } \\
\text { Coping styles. } \\
\text { Attachment profiles. } \\
\text { Mood, anxiety and trauma-related disorders. }\end{array}$ & $\begin{array}{l}\text { Adverse life events. } \\
\text { Stress. } \\
\text { Poor relationships. } \\
\text { Symptom modelling (eg, of family } \\
\text { members). }\end{array}$ \\
\hline Precipitating mechanisms & $\begin{array}{l}\text { Physical injury; strain/pain; surgery; medical illness. } \\
\text { Habituated muscle tension patterns; dysregulated } \\
\text { movement patterns; excessive inhibition of } \\
\text { movement. } \\
\text { Viral infection affecting upper or lower respiratory } \\
\text { tract. } \\
\text { Inhaled toxic substances. } \\
\text { Exposure to noxious odours. } \\
\text { Historical or recent choking incident with persisting } \\
\text { belief something still caught in the throat. } \\
\text { Drug/medication induced side effect. }\end{array}$ & $\begin{array}{l}\text { Dilemmas with forced choices leading to } \\
\text { negative consequences. } \\
\text { Ambivalence over expression of negative } \\
\text { emotions, conflict over speaking out, sense of } \\
\text { entrapment. } \\
\text { Anticipation of difficult encounter, illness or } \\
\text { pending surgical procedure. }\end{array}$ & $\begin{array}{l}\text { Significant adverse life events } \\
\text { Interpersonal stress }\end{array}$ \\
\hline Perpetuating factors & $\begin{array}{l}\text { Hypersensitivity to subtle changes in air pressure, } \\
\text { temperature, sensation in respiratory and vocal tract. } \\
\text { Physiological arousal. } \\
\text { Pain. }\end{array}$ & $\begin{array}{l}\text { Fear-avoidance. } \\
\text { Tendency to 'all or nothing' or catastrophic } \\
\text { thinking. } \\
\text { Perception that voice use or swallowing are } \\
\text { dangerous, harmful, effortful. } \\
\text { Hypervigilance and excessive self-monitoring. } \\
\text { Belief that symptoms are due to damage } \\
\text { or suspected or confirmed disease/illness; } \\
\text { unusual illness beliefs. } \\
\text { Entrenched symptoms have become part of } \\
\text { one's sense of self or personal identity. }\end{array}$ & $\begin{array}{l}\text { Litigation or disability compensation } \\
\text { issues. } \\
\text { Medical uncertainty. } \\
\text { Excessive reliance on unreliable } \\
\text { Sources of information. } \\
\text { Stigma. }\end{array}$ \\
\hline
\end{tabular}

A given factor may cut across a range of components within the biopsychosocial formulation. For example, in some individuals altered threat/emotion processing may be both a predisposing vulnerability and a perpetuating factor. 
Table 2 Positive clinical features of functional communication and swallowing disorders

\begin{tabular}{|c|c|}
\hline Positive clinical signs of FND & General examples in functional communication and swallowing disorders \\
\hline $\begin{array}{l}\text { Symptoms are inconsistent with clinical } \\
\text { examination and laboratory/imaging findings }\end{array}$ & $\begin{array}{l}\text { Severity of speech deficit is disproportionate to severity of injury or locus of lesion (eg, single lacunar stroke; mild traumatic } \\
\text { brain injury). }\end{array}$ \\
\hline Symptoms are internally inconsistent & $\begin{array}{l}\text { Resolution or reduced severity during small talk or other spontaneous discussion, when attention is diverted, or during } \\
\text { natural automatic functions, preverbal and/or automatic utterances, playful, emotionally expressive activities, during laryngeal } \\
\text { manipulation (voice disorders).* }\end{array}$ \\
\hline $\begin{array}{l}\text { Symptoms are associated with inefficient and non- } \\
\text { ergonomic patterns of movement }\end{array}$ & $\begin{array}{l}\text { When weakness is major complaint, speech, voice, swallowing fatigues in the direction of muscle hyperfunction. } \\
\text { Struggle behaviours - overmouthing, eye blinking, facial contortions, excessive effort in breathing, neck, shoulders, strap } \\
\text { muscles, shifts in body posture-including during non-speech oromotor tasks. }\end{array}$ \\
\hline
\end{tabular}

* Note that many structural/neurological communication disorders can show symptom fluctuations. The core difference is that in structural/neurological cases one can discern plausible predictability in how/when/where symptoms vary — for example, in relation to fatigue, time in medication cycle, cognitive load and language variables such as word frequency, syllable complexity stress placement in word/sentence. These underlying regularities tend not to be present in functional communication and swallowing disorders.

FND, functional neurological disorder.

\section{TREATMENT}

In general, the broad principles of treatment of functional disorders of communication, swallowing and cough are the same as for other FNDs. ${ }^{29-31}$ The first and most important part of treatment involves making a positive diagnosis (ie, based on symptoms consistent with FND and not solely based on ruling out other explanations) and clearly explaining the diagnosis and the reasons for it to the patient. ${ }^{28} 32$ This explanation may have therapeutic value in its own right. Subsequent therapy may include symptomatic, behavioural and/ or psychological interventions along with ongoing education about the diagnosis.

\section{Explaining the diagnosis}

In explaining the diagnosis, it is important to (1) take the problem seriously and acknowledge that the symptoms are real, (2) explain that this is a positive diagnosis (as defined above) and that the diagnosis is not unknown or mysterious, (3) explain the reasons for the diagnosis by demonstrating or explaining its positive clinical signs (box 3), (4) provide written material and links to other resources. Suggestions to help with effective explanations are listed in box 4 .

When the person referred for treatment has already had the diagnosis explained by the referring professional, it is still important for the speech and language professional to reinforce, consolidate, and, if necessary, expand the person's understanding about the functional disorder diagnosis. When there is comorbid structural pathology, the therapist may need to discuss the extent to which it may or may not be an obstacle to improvement. ${ }^{33-38}$

\section{Duration of treatment}

Most patients referred with functional disorders of communication, swallowing and cough can benefit from speech and language therapy, often substantially/dramatically and sometimes rapidly. Many achieve some improvement or even elimination of one or more, and sometimes all of their symptoms during the initial consultation. While this does not necessarily mean that the functional disorder has fully resolved, such early symptomatic improvement is very encouraging. Others require several therapy sessions of symptomatic/ behavioural work, integrated with counselling. Clinical experience suggests that intensive therapy, with sessions several times per week, may be most successful in helping patients to regain normal function and inhibit abnormal movements or struggle behaviours, and to maintain gains in the wider social context. We recognise, however, that limited resources may limit the frequency of therapy.

For some, several weeks or months of treatment may be required for a sustained improvement that generalises beyond the clinical setting. This has sometimes been attributed to the patient 'being resistant' or 'failing to comply' with recommendations, but generally speaking, patients do want to improve-that is why they are there-and are cooperative with treatment. Habituated patterns of movement and behaviour can take time and practice to overcome, and there may also be perpetuating influences (see table 1). Some therapists find it useful to develop a time-limited treatment contract which includes indications for ending therapy, a

\section{Box 3 Demonstrating clinical signs}

Some practitioners feel uncertain about demonstrating clinical signs of functional disorders to patients in the clinic; however, in our experience this is almost always a positive experience for patients. $^{32}$

For example (not real cases):

- A middle-aged man presented with sudden onset of functional falsetto characterised by an unusual high-pitched falsetto voice. The therapist asked him to produce a strong/ ooh/sound while palpating, tilting and manually repositioning his larynx, demonstrating that normal lower-pitched voice was possible.

- A woman presented with a severe functional aphonia. During videolaryngoscopy examination, the otolaryngologist made a humorous aside about his poor golf swing and the patient laughed politely. The therapist pointed out that during that spontaneous laughter, it was possible to see the sudden relaxation of the tightly constricted false vocal folds that was inhibiting the function of the true vocal folds, thus revealing the potential for normal function.

- A recently retired man presented with sudden onset of moderate-to-severe dysfluency characterised by whole word and initial phoneme repetition with speech blocks. The therapist asked him to speak on a topic while focusing on sequentially tapping each of his fingers with his thumb, beginning on the left hand then continuing with the right. Moments of stuttering reduced from 25 in a 1 min monologue to just two, demonstrating the effect that distraction had and the ability to easily produce smooth, stutter free speech. 
Box 4 Explaining the diagnosis

Important elements of the explanation of a functional communication, swallowing and other upper airwayrelated (eg, cough and breathing) disorder

Although we have used the term 'functional disorder' for consistency, we understand that a range of terms may be used to describe these conditions. For example, cough might be more clearly explained in terms of hypersensitivity or hyperresponsiveness. We also recommend that the explanation be tailored appropriately to the patient's level of understanding. Examples of explanatory phrases used by the authors are listed below:

Take the problem seriously

- 'These symptoms are real and not 'in your head'.

- 'This is a genuine problem, and I believe you'.

- 'I imagine this must be making things at work/home really difficult'.

Name the diagnosis

- 'You have a functional speech disorder affecting your articulation'.

- 'You have a functional stuttering problem affecting your fluency'.

- 'This sensation of a lump in your throat is called functional globus'.

- 'This is a type of functional neurological disorder'.

Explain the diagnosis in terms of what it is rather than saying what it is not

- 'The symptoms are caused by abnormal brain functioning rather than structural damage or disease.'

- 'A software problem, not a hardware problem.'

- 'Software not broken, but has a glitch.'

- 'The machinery is still present and whole, but someone switched the outlets so now when it gets plugged in, it doesn't work smoothly anymore. We need to switch the outlets back.'

- 'The server is busy.'

- 'Your muscles have the potential to work properly but the messages are having problems getting through.'

- 'The train is off the tracks. The train and the tracks are both working correctly but only run smoothly when properly aligned.'

- 'Your brain has forgotten the path to produce voice for speech; we need to find the path to the voice again and memorise that feeling.'

- 'For a time you couldn't use the most efficient route (The Motorway) and instead needed to use a 'B road' to make the movement. Now we know the Motorway is open, which will be more efficient, we can help you to use the Motorway consistently again.'

- In explaining aetiology, using the analogy 'sometimes people throw their back out but don't know what happened' and explain that the body can respond to experiences that we are not acutely aware of.'

- 'Describe other non-structural causes of physical symptoms: stomach ache before an important exam; headache from a stressful day at work; shoulder/neck/arm tension from being tense over some issue.'

- Explain that throat muscles are particularly vulnerable to stress/anxiety (analogy of lump in throat when cross/ upset/holding back tears) and when they get into a habit of tightening it can alter how our voice sounds, contribute to

Continued

\section{Box 4 Continued}

breathing difficulties and cough. They need to be shown how to relax/release.

- 'You have very efficiently learnt how to use your voice (clear or protect your airway) when you needed this protection. This learning was so helpful that you kept using it when it was no longer necessary. Now you no longer need this technique and may benefit from reacquainting yourself with how you previously spoke (breathed, swallowed, etc).'

- Explain conditioned learning (eg, 'Pavlov's dogs'), especially when symptoms are intermittent, paving the way to 'unlearning' with treatment.

- Explain 'your brain is clever, and it knows that you need to stop and look after yourself'.

- Explain the diagnosis using a sketch of a straight line balanced on the tip of a triangle, and discuss the importance of a balance between capacities and demands (bringing into the explanation the Demands and Capacities Model; when demands (internal and external) exceed capacity (compromised by pain, headache, sleep deprivation, etc), the neurological demands on the brain's finite resources are compromised. Use the analogy of demands as noise in the brain, impacting the finite synapses we depend on for rapid transmission and storage of information (capacities).

Explain and demonstrate the rationale for the diagnosis. Explain that the presence of variability suggests that improvement should be possible with treatment.

- Demonstrate and explain positive clinical features, for example, 'When you imitated my voice in this way, I was able to hear your voice, even though momentarily. This suggests that the vocal cords are able to move normally when automatic control takes over, and tells us that we should be able to get your voice working normally again and back under your voluntary control.'

Provide written information and direct to other resources

- Printed symptom information sheets.

- Online information such as www.neurosymptoms.org.

- It is good practice to write clinical letters to patients when possible, and to enable access to clinical reports when respective specialists give permission.

plan for self-management and strategies for coping with possible relapse of symptoms.

\section{Suitability for treatment}

Factors important for engagement with treatment include: (1) a reasonable degree of understanding and agreement with the diagnosis and (2) motivation and agreement to treatment.

Circumstances in which beginning or continuing symptomatic therapy is less likely to be successful or may be inadvisable, and which suggest a guarded or poor prognosis in some cases include:

- Transient, unpredictable or highly variable symptoms across settings.

- Resolution or improvement of symptoms will lead to a return to what may be an unsafe or 'futile' work environment or domestic situation.

- Unresolved litigation related to symptoms.

- Severe psychiatric comorbidity.

- Other severe FND symptoms are present, such as seizures, dissociative states, severe pain or fatigue. However, early 
treatment of communication symptoms may enable the person to engage better with treatment of the other symptoms.

- Patient doubts the diagnosis of FND, although some may accept/embrace it during successful symptomatic treatment.

- Poor confidence in therapist's ability to help them resolve symptoms.

A trial of therapy is generally appropriate despite a degree of resistance or ambivalence. However, some positive response to treatment should be expected during the first 1-2 sessions; failure to respond at all during these initial sessions suggests it would be better to pause and revisit symptomatic treatment at a later date, or with another therapist.

\section{General principles of symptomatic treatment}

The principles of symptomatic management of functional communication, swallowing, and cough disorders can be helpfully informed by both perceptual-motor learning models as they have been applied to voice training and therapy ${ }^{39} 40$ and recommendations from physiotherapy and occupational therapy professionals with experience treating FND. ${ }^{6} 7$ Treatment involves learning or retraining of motor patterns, while highlighting the ways in which attention, expectations, illness beliefs and the vulnerability of our sense of agency (the experience of controlling one's own movements) may inhibit normal movements and promote abnormal movements.

\section{Identify symptomatic behaviours and explain the mechanism of the symptom}

It is important to explain how the patient's symptoms differ from those associated with normal speech, voice, swallowing or cough and then to draw attention to the inadvertent and unnecessary efforts being used in particular muscle groups, such as in the head and neck, face, upper torso and shoulders; for example, patients are often surprised to learn that even producing a hoarse whisper can reflect excessive effort. Acknowledging how tiring and distressing it can be to exert such effort may prompt a reaction of relief or gratitude when the patient senses someone understands what they have been experiencing.

\section{Introduce strategies to facilitate natural automatic patterns of movement}

A common key feature of symptomatic treatment involves finding ways to access natural automatic movement patterns.

\section{Regain voluntary control over conscious initiation of speech, phonation, swallowing, etc}

In addition to facilitating natural automatic movement patterns, in some cases the aim will be to trigger highly volitional utterances that will be simply different from the abnormal speech pattern. It may not necessarily be normal, but it will be different, and it can then be shaped towards normal. The therapist may then invite the person to extend these different or natural automatic patterns of movement into familiar and well-learnt sequences that require little conscious thought or planning. The schemas for these automatic sequences tend to be locked into our procedural memory which are revealed when we ask a person to engage in well-learnt and practised tasks which they are able to do largely without detailed awareness of what has been learnt. ${ }^{3941}$
4. Extend automatic activities into graded, functionally relevant and meaningful activities

When the therapist asks the patient to do these automatic and well-learnt sequential tasks, many will be able to complete them successfully (even if only tentatively at first). However, if the patient is clearly reticent, the therapist may introduce a number of additional activities in order to distract the patient's attention from their own performance. For instance, during verbal tasks the therapist may introduce ways to momentarily mask the patient's auditory feedback of their own voice and speech which will then help to trigger a reflexive vocal response. Distraction of attention can serve to block the patient's heightened sensitivity to auditory feedback which may have prompted a self-conscious inhibition of their voice or speech. ${ }^{42} 43$

For many patients, it can be an exciting moment to hear their speech, voice and fluency returning to normal once again, or to realise they have swallowed some fluid without choking. For some, their relief may trigger laughter or tears. For others it can be an uncomfortable experience and may even stimulate an escalation in the severity of their involuntary symptomatic behaviours. Here it is important for the therapist to confidently persist with the interventions, reassuring the patient that it is not unusual for their speech or swallowing patterns to go through different stages as it returns to normal, and that they intend to persevere with them through this transition phase if the patient wishes to continue.

\section{Positive and negative practice between old and new}

Distraction or diverted attention is not always necessary, and some find it helpful to guide the patient to allocate all attentional resources to positive (auditory, kinaesthetic, vibrotactile) changes that take place during the course of therapy. This is an essential component of positive/negative (new way/old way) practice; paying attention to how the new pattern feels compared with the old disordered pattern aids a sense of voluntary control and mastery.

\section{Consolidate and generalise normalised behaviours into wider social context}

The next step is to extend these improved utterances or behaviours into graded and meaningful, task-oriented activities that will eventually culminate in conversation, swallowing comfortably during social mealtime eating and drinking, or managing symptoms of cough in different settings. In keeping with another key principle of perceptual-motor learning, findings suggest that conscious self-focused attention on the minutiae of the mechanics of motor tasks affects both performance and learning negatively. In contrast, focused attention on the target of the activity and the desired outcomes of the task are generally more beneficial.

\section{Help the patient to notice and challenge unhelpful thoughts}

Incorporating principles from cognitive-behavioural therapy (CBT) can aid treatment of FND, and there have been promising results from trials of specific CBT for functional movement disorders and dissociative seizures, ${ }^{3144} 45$ functional communication, swallowing, cough disorders and specifically in relation to voice. ${ }^{46-49}$ CBT principles can inform therapy even without formal CBT training. For example, by helping the patient to notice and challenge unhelpful automatic thoughts, such as catastrophising (eg, 'If I stutter at work I'll lose my job'; 'once I start coughing I won't be able to stop'); or 'all or nothing' thoughts like 'If my voice isn't perfect all the time then I'm a failure' or 
'swallowing is sometimes hard so it is better if I never eat in public'. Behavioural strategies might include helping the patient to plan 'behavioural experiments'-such as a telephone call, or coffee with a friend - to address fear and avoidance of specific activities.

\section{Address psychosocial predisposing and perpetuating factors}

Many patients with FND will have rapid and successful resolution of symptoms without the need to explore psychological or social risk factors, which may not be relevant. However, some patients will wish to explore the relevance of psychological or social factors as therapy progresses. From a purely practical point of view, it is easier to address those influences once functional symptoms are no longer interfering with communication. We emphasise that the therapist can helpfully and appropriately engage in supportive discussion about the role of anxiety, or about the impact that symptoms have had on relationships and everyday life, without special training in counselling or psychotherapy. These discussions might, for example, help the patient to plan for situations where symptoms may recur, and allow them to explore how best to manage future relapses.

In the more unusual situation in which a patient becomes extremely distressed or psychiatrically unwell during treatment, a plan for additional or alternative management should be made, incorporating the patient's general practitioner/family doctor, other members of the multidisciplinary team (eg, psychiatry or psychology), or referral to a mental health professional or crisis services as available locally. ${ }^{50}$

A final stage of treatment often involves encouraging the ongoing involvement of family, friends and caregivers, and re-establishing the links to and support from the patient's workplace and work colleagues.

\section{Prepare strategies for dealing with setbacks or relapse}

Patients should be prepared for the possibility of relapse, with the emphasis on enabling them to self-manage any relapse using the techniques used during therapy. Clear criteria should be provided to the patient and referrer, or other members of the multidisciplinary team, about how and when future therapy should be sought; this advice should be provided on a case-bycase basis and obviously may depend on service constraints. However, in general we recommend that further treatment or support be made available in case of relapse. As emphasised in a discussion paper addressing ways to end therapy 'the therapeutic relationship once established need never be broken, ${ }^{51}$

\section{Assessment, diagnosis and treatment of specific symptoms}

The following sections address specific symptoms. However, it should be noted that these specific symptoms are not mutually exclusive but often co-occur. An individual may experience a range of different symptoms at different times, including during treatment and recovery. The treatment strategies suggested here are based on available evidence and the combined clinical experience of the consensus group. They largely represent recommendations rather than high-level-evidence-based guidelines.

\section{Specific symptoms: functional voice disorders}

Functional voice symptoms include dysphonia, aphonia, odynophonia (pain using the voice), vocal fatigue and mutational falsetto or puberphonia (high pitched voice after puberty). Globus is common, and excessive physical effort is a hallmark feature of these disorders. There is a (usually) sudden or intermittent loss of volitional control over the initiation and maintenance of phonation despite normal structure and function as observed during laryngoscopy and clinical examination. Since the voice is often closely associated with the expression of emotion, sudden total or partial loss of voice is often presumed to be linked to psychological factors and negative emotions associated with stress. Furthermore, patterns of vocal hyperfunction related to dysregulated or imbalanced laryngeal muscle activity are often observed, both of which are consistent with current FND models that emphasise the interplay between 'top down' and 'bottom up' influences on peripheral sensorimotor processing. ${ }^{52-54}$ As a consequence, in the past these disorders have often been referred to as 'psychogenic', or 'conversion dysphonia', with others more recently preferring the more aetiologically neutral term of 'functional' or 'primary muscle tension dysphonia'. ${ }^{85}$

Onset may follow acute stress or longer-term difficulties, sometimes characterised by conflict over speaking out, expressing negative emotions, a sense of powerlessness; sometimes related to personality vulnerabilities. ${ }^{18} 5657$ Importantly, many patients do not recall any emotionally stressful incidents, but will associate their loss of voice with a recent upper respiratory tract infection, a medical procedure involving the head and neck, or some form of blunt injury which cannot account for the nature and severity of the vocal symptoms. Therapists often comment that while some patients do not report or recall significant stresses prior to onset, once they have their voice back, they might reopen conversations about possible psychosocial triggers. Helpful assessment methods and diagnostic features are listed in the full version (see online supplemental file 1).

Treatment includes strategies to bypass problematic movement patterns by facilitating short, instinctual responses and overlearned or reflexive utterances (table 3). It is advisable to inform patients that you are going to ask them to do some things differently which may entail making unusual sounds or carrying out gestures or bodily movements not associated with their usual way of talking. These activities can elicit normal phonation easily, without conscious preparation, since they are neither generally associated with use of the voice, nor are they experienced as being directly related to a conscious intent to communicate. If they were, they may trigger patterns of inhibitory muscular tension and exaggeration of the symptoms.

Specific treatment strategies may be necessary to reduce excessive musculoskeletal tension when present. They may include focal palpation of the laryngeal region, circumlaryngeal massage and manual repositioning with gentle but firm lowering or compression of the larynx (when within professional scope and competence). ${ }^{5859}$ The speech and language professional should reassure the patient that their pattern of excessive tension does not represent an irreversible muscular abnormality, but rather reflects a well-intentioned, but misdirected effort to achieve normal voice. Just prior to touching the neck, throat and larynx, it is important to explain what the clinician will do and why, and to ask permission to palpate, massage or reposition the larynx.

Use of traditional evidence-based techniques for dysphonia such as Vocal Function Exercises, Semi-Occluded Vocal Tract Exercises, and Resonant Voice Exercises may be useful for modifying voice, consolidation and generalisation.

Once normal phonation has been achieved, generalisation beyond the clinical setting is relatively straightforward, but it can be particularly challenging for some individuals in specific psychosocial contexts (ie, a schoolteacher returning to the classroom after developing functional aphonia following significant difficulties in managing rebellious student behaviours and lack of support from school leaders). Under these circumstances, sustained improvement may be difficult to achieve, especially 
Table 3 Treatment of functional voice disorders

\begin{tabular}{|c|c|}
\hline $\begin{array}{l}\text { Domains of } \\
\text { intervention }\end{array}$ & Examples of possible strategies \\
\hline $\begin{array}{l}\text { Education and } \\
\text { explanatory }\end{array}$ & $\begin{array}{l}\text { A key part of treatment is clear explanation of the nature of the disorder (see box } 4 \text { for helpful phrases) and the rationale for the diagnosis. } \\
\text { Review the laryngoscopy examination and/or images together with the patient. It is particularly important to explain that 'abnormal movements' and similar } \\
\text { remarks in written reports reflect reversible habitual movements and not irreversible structural abnormality, as patients may misunderstand the implications of } \\
\text { such phrases. } \\
\text { Explain that voice disorders can result from excessive muscle tension which may prevent normal speech but does not represent an irreversible or } \\
\text { uncontrollable abnormality and that it can brought under their control. }\end{array}$ \\
\hline Symptomatic & 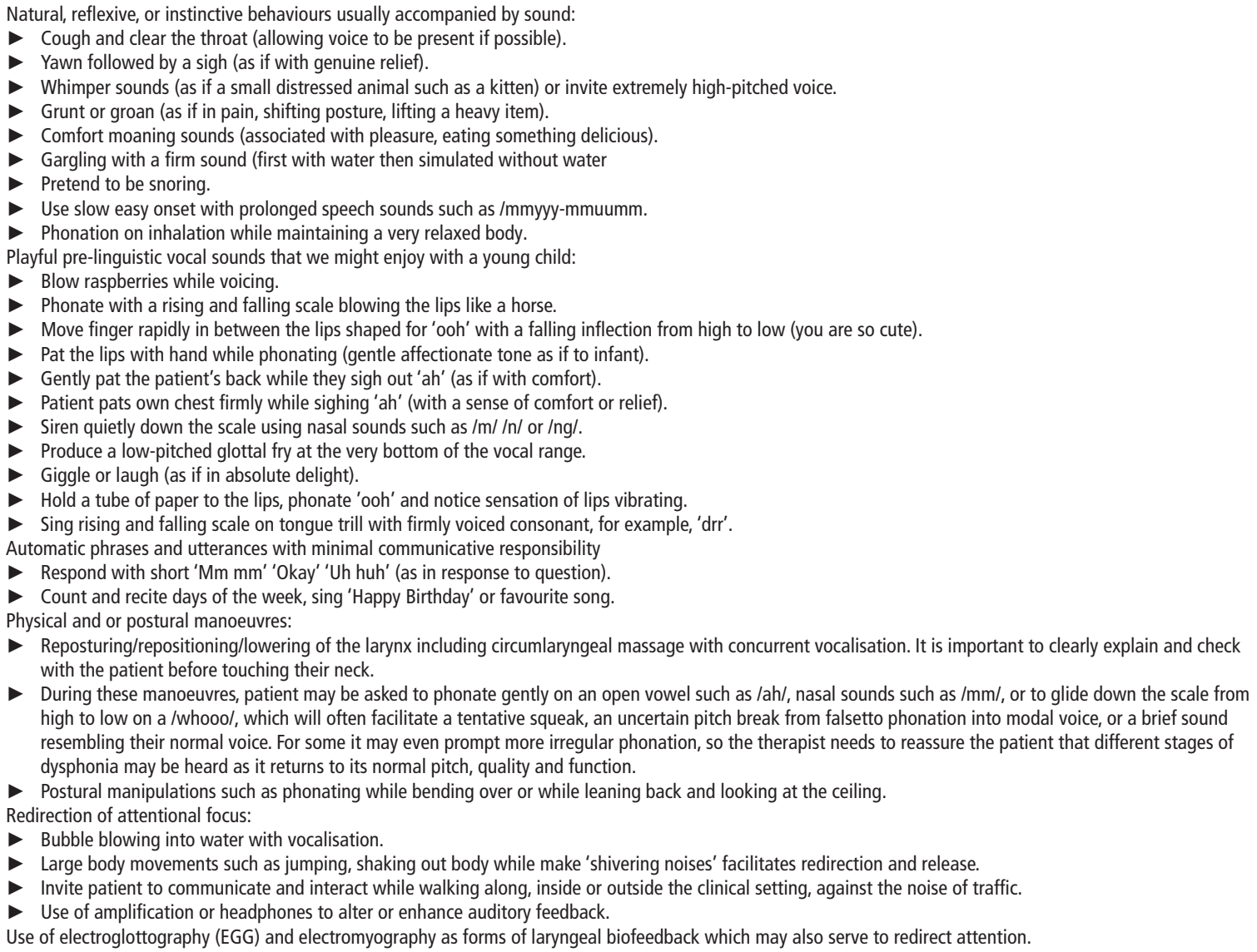 \\
\hline Psychological & $\begin{array}{l}\text { Communication counselling attending to predisposing, precipitating and perpetuating issues related to onset and maintenance of voice symptoms. } \\
\text { Identify and gently address patterns of avoidance of speaking or excessive dependence on aids to communication. } \\
\text { Identify any social or other phobic anxiety, that is, of speaking in particular situations. Support to increase exposure (and so reduce anxiety) to feared } \\
\text { situations. In some cases collaborative work with, or onward referral to, mental health professionals for structured psychotherapy (eg, CBT) may be helpful. }\end{array}$ \\
\hline
\end{tabular}

if there is evidence of long-standing anxiety, comorbid depression or ongoing medicolegal or workers' compensation issues. ${ }^{43}$ Outcomes are more likely to be positive if the patient understands the relationship between the voice problem and any ongoing psychosocial issues and has strategies in place to deal with them. Basic supportive counselling (and use of additional psychological approaches within individual scope) by the speech and language professional is often sufficient, but referral for additional support from a mental health professional is sometimes essential. ${ }^{48} 4960-62$

Systematic reviews of randomised controlled trials exploring the efficacy of symptomatic voice therapy for 'functional dysphonia' report moderate-to-good evidence for the direct symptomatic and behavioural voice therapies, either alone or in combination with indirect therapies that may involve education and vocal hygiene. ${ }^{6364}$ More recently an extensive evaluation of the evidence for the efficacy of therapy for functional and structural neurological voice disorders has shown similar findings. ${ }^{65}$ These studies did not appear to distinguish between patients within their broadly defined functional dysphonia groups (ie, no structural abnormality) and those traditionally termed 'psychogenic/conversion aphonia dysphonia' as being discussed in this paper.

Another subtype of functional communication disorders is functional mutism, in which the patient does not produce sound, even with a whisper, or may mouth words with accurate but inaudible articulatory movements. This is in contrast to selective mutism which reflects voluntary refusal to speak, sometimes only in specific circumstances (often in the context of anxiety). In functional mutism the inability to speak is experienced as involuntary. Selective mutism and functional mutism sometimes overlap. In some cases the history reveals a breakdown in communication with significant others, and/or there is a conflict over speaking out or expressing negative emotions. The person may ask for access to an electronic device to assist with communication, which raises interesting issues about offering aids that may serve to perpetuate the ongoing pattern of mutism. When possible, communication without aids should be encouraged. 


\section{Specific symptoms: functional stuttering}

Functional stuttering is distinguished from developmental or neurogenic stuttering by new onset in adulthood (without prior developmental speech output difficulties), extremes of variability or consistency on sound, syllable, word or phrase repetitions, unusual patterns of rate and pausing, increased dysfluency with more simple speech tasks, and lack of improvement with activities that usually promote fluency. Of note, functional dysfluency may be internally inconsistent but may also be unusually consistent in presentation compared with developmental stuttering, such as stuttering on every syllable or word, or on the first word of every sentence. ${ }^{34}$ 66-68 Helpful assessment methods and positive diagnostic features are shown in the full version (see online supplemental file 1 ).

Case reports suggest functional dysfluency may follow stressful life events associated with conflict and difficulties with communication of negative emotions in close relationships or with an important person; dealing with high burden of responsibility or criticism in the work place where it is difficult to speak out and defend oneself; recent accident or illness sometimes in association with mild head injury leading to transient concussion; in situations where personal injury lawsuit or workers compensation may be an issue; or in association with posttraumatic stress disorder following combat. Clinicians emphasise that close attention needs to be given to these psychosocial issues, while also recognising that the absence of a clear psychological trigger should not discount a functional diagnosis. Functional dysfluency can co-occur with other functional neurological symptoms, and in patients with comorbid neurological disease including stroke, epilepsy or traumatic brain injury. ${ }^{38} 676970$
Although positive outcomes have been reported in case studies of treatment of functional stuttering in adults, it remains unclear what elements of these treatments explain their effectiveness. ${ }^{38}{ }^{67}$ Some potential approaches to symptomatic treatment are summarised in table 4 .

When functional dysfluency does not resolve quickly with treatment, psychological impacts can be severe. Generalised anxiety and social anxiety in anticipation of speaking activity have significant implications for self-identity, close relationships, social participation and quality of life. While diagnosis of a psychological disorder is outside the scope of practice for speech language professionals, recognition of psychosocial factors in functional stuttering (as in developmental stuttering) allows therapists to appreciate the lived experience of stuttering and to guide appropriate therapy. Alongside symptomatic treatment, the therapist might helpfully include psychological approaches targeting features of avoidance, rumination and self-doubt. ${ }^{71} 72$ As with developmental and neurogenic presentations of stuttering, collaboration with mental health professionals may be helpful in the management of secondary anxiety disorders and psychological distress. $^{73}$

\section{Specific symptoms: functional articulation symptoms}

Functional articulation disorders are characterised by substitutions or distortions of specific sounds, some of which may be associated with developmental errors (eg, 'wead'/'read', 'wittle'/little', 'thome thoap'/'some soap'). Some sounds are produced with marked variability and unusual and exaggerated tongue, lip or jaw movements. These distortions may be accompanied by other unusual prosodic features, such as inappropriate

Table 4 Treatment of functional dysfluency/stuttering

\begin{tabular}{|c|c|}
\hline Domains of intervention & Examples of possible strategies \\
\hline Education and explanatory & $\begin{array}{l}\text { Reassurance regarding nature of symptoms and good prognosis for resolution. } \\
\text { Explanation for rationale behind diagnosis of functional stuttering. } \\
\text { Explanation that dysfluencies can reflect effects of excessive muscle tension which may prevent normal speech but does not represent an irreversible } \\
\text { or uncontrollable abnormality and that it can brought under their control. }\end{array}$ \\
\hline Symptomatic & $\begin{array}{l}\text { Reduction of excessive musculoskeletal tension in both speech and non-speech muscles often associated with stuttering: } \\
\text { Reduce muscle tension, drawing on techniques used for functional voice disorders. } \\
\text { Select high frequency abnormal behaviours associated with dysfluencies. } \\
\text { Palpate or manipulate facial muscles or lower the larynx to reduce muscle tension. } \\
\text { Eliminate secondary or accessory movements which may involve asking them to do something differently or adding a distraction which is faded out as } \\
\text { speech normalises } \\
\text { Speak while lying on their back. } \\
\text { Invite person to squeeze a ball while speaking. } \\
\text { Invite person to sort blocks into different patterns while speaking. } \\
\text { Suggest finger tapping thumb and finger while speaking. } \\
\text { Speak while listening to music through headphones. } \\
\text { Modification of stuttering behaviours } \\
\text { Once excessive tension has been reduced, and the patient can produce some sounds, words or phrases with less struggle, normal speech may return in } \\
\text { some cases. If not, it may be appropriate to introduce techniques currently used successfully for the treatment of developmental stuttering such as: } \\
\text { Speech restructuring and fluency shaping techniques, for example, the Prolonged Speech Treatment Model, the Camperdown Programme } \\
\text { for adults who stutter, or the La Trobe Smooth Speech Clinic Programme. } \\
\text { These intensive treatment programmes offered individually or in groups may include: } \\
\text { Slowing rate of speech. } \\
\text { Easy, gentle onset. } \\
\text { Elongating vowels and producing prolonged speech. } \\
\text { Linking words together with controlled phrasing. } \\
\text { Emphasising speech naturalness. } \\
\text { Determining hierarchy of speaking situations with desensitisation tasks. }\end{array}$ \\
\hline Psychological & $\begin{array}{l}\text { Communication counselling attending to predisposing, precipitating perpetuating issues related to onset, presentation, and maintenance of stuttering } \\
\text { behaviours. } \\
\text { Address abnormal illness beliefs, excessive attention and vigilance towards bodily sensations, and the sense of loss of control over speech fluency. } \\
\text { Teach person to respond to moments of stuttering and feelings of loss of control in more adaptive ways, using less struggle and tension which can be } \\
\text { beneficial, both psychologically and physically. }\end{array}$ \\
\hline
\end{tabular}


Table 5 Treatment of functional articulation disorders

\begin{tabular}{|c|c|}
\hline Domains of intervention & Examples of possible strategies \\
\hline Education and explanatory & $\begin{array}{l}\text { Reassurance regarding nature of symptoms and good prognosis for resolution. } \\
\text { General principles already discussed as for functional voice and fluency including their understanding of diagnosis, the rationale for current diagnosis. } \\
\text { Education about how we actually speak vs how we think we speak for example, we do not necessarily pronounce words according to spelling. }\end{array}$ \\
\hline Symptomatic & $\begin{array}{l}\text { Reduction of excessive musculoskeletal tension in speech and non-speech muscles often associated with articulation: in head, neck, shoulders, face and } \\
\text { mouth. } \\
\text { Where there is functional facial weakness, spasm, or trismus, collaborative treatment with physiotherapy or occupational therapy may be helpful. } \\
\text { Eliminate secondary or accessory movements which may involve the patient doing something differently, which acts as a distraction, later to be faded } \\
\text { out as speech normalises. } \\
\text { Focusing on normal movements and sounds, distracting from abnormal sounds, etc. } \\
\text { Dual tasking while speaking as form of distraction. } \\
\text { Invite non-speech articulation such as singing. } \\
\text { Introduce skills in 'mindfulness' during oromotor tasks as a way of maintaining focus on easy, smooth movements where possible. } \\
\text { Slow speech down or elongate a sound rather than building tension around it, which can be explained as 'resetting the system'. } \\
\text { Use nonsense words or syllable repetitions as way to demonstrate potential for 'normal' function. } \\
\text { Advance communication with higher cognitive linguistic content in hierarchical fashion (similar to the strategies for functional voice and stuttering). } \\
\text { Redirect patient focus on speech to other topics, monitoring if speech improves and in which contexts. } \\
\text { If functional voice or fluency problems are also present the treatment of a single communication problem may result in resolution of all communication } \\
\text { symptoms. }\end{array}$ \\
\hline Psychological & $\begin{array}{l}\text { Attention to psychosocial issues as for other symptom groups. } \\
\text { Address cognitive features related to locus of control, executive function, abnormal illness beliefs, hypervigilance to bodily functions, etc. } \\
\text { Help person gain insight into the positive changes in articulation, and how they are achieving more normal control over speech movements. }\end{array}$ \\
\hline Psychological & $\begin{array}{l}\text { Counselling by the speech and language professional in relation to psychological and life stresses contributing to symptoms. } \\
\text { Education about the physiology of anxiety, the anxiety arousal curve, and the importance of avoiding avoidance. } \\
\text { Treatment of any comorbid or secondary psychiatric disorder for example anxiety, depression, phagophobia. } \\
\text { Cognitive Behavioural Therapy strategies may be useful. Identify and challenge: } \\
\text { - Beliefs and cognitions, for example, 'food will stick in my throat' 'I will choke and die'. } \\
\text { - Self-reported sensations, for example, 'My throat feels tight and narrow' 'Food is sticking there and won't move'. } \\
\text { - Maladaptive behaviours, for example, avoidance of solids, withdrawing from others, eating in isolation. } \\
\text { Self-directed attention, for example, preoccupations with throat sensations 'Chewing is hard, swallowing is difficult'. } \\
\text { Recommend positive self-statements during the swallow such as 'my throat feels easy', 'this swallow is easy'. }\end{array}$ \\
\hline Medical & $\begin{array}{l}\text { Provide information and advice to reduce acid reflux. Signpost for appropriate medical management of acid reflux and/or post nasal drip if present. } \\
\text { Selective Serotonin Reuptake Inhibitor (SSRI) antidepressants or low-dose amitriptyline may be helpful for globus. }\end{array}$ \\
\hline
\end{tabular}

patterns of loudness, with telegraphic speech and hesitations or exaggerated facial movements. Errors may be consistent and limited to particular sounds, or unusual and associated with unusual tongue posturing (eg, speaking with consistent tongue retraction). The patient may complain of weakness while exhibiting paradoxical strained voice quality. Functional articulation symptoms sometimes develop after dental, surgical or traumatic injury to the mouth, tongue or facial structures, or in combination with other functional symptoms affecting voice or fluency. ${ }^{57475}$ Examination features are detailed in the full version (see online supplemental file 1).

In addition to the general treatment approaches outlined above, traditional treatment approaches used for developmental and neurological articulatory disorders may be effective. Some treatment strategies are suggested in table 5.

\section{Specific symptoms: other functional communication disorder symptoms (eg, language, prosody and accent)}

Language impairments impacting on understanding, word finding, syntax, reading and writing may occur in FNDs, often along with other functional cognitive symptoms. ${ }^{76}$ Diagnosis is generally made on the basis of significant internal inconsistency in performance compared with well-described lesion-based patterns of aphasia, dysgraphia and alexia. An example of such inconsistency would be disproportionate difficulty with reading during formal assessment in comparison to day-to-day reading. In some cases, however, these problems may be abnormally consistent in comparison with lesion-based aphasia, dysgraphia, etc.

Subjective word finding or memory and concentration difficulties are not uncommon in patients with FND, and often appear to reflect inefficient allocation of attentional resources. Once other speech or communication symptoms, or other functional symptoms, are effectively treated, such cognitive symptoms may resolve. If the symptoms persist, some patients may benefit from being taught simple compensatory strategies for word retrieval deficits and similar difficulties.

FAS is a disorder of speech in which listeners perceive the affected individual as speaking with a foreign or regional accent. Onset of FAS may occur in neurological disease or damage, for example after stroke or brain injury. Recent review of cases of selfreported FAS suggest that in some cases symptoms are the result of an FND. Functional FAS can be identified by the presence of internally inconsistent changes in the person's articulation and prosody, alterations to vowel and consonant production, stress, rhythm and intonation ${ }^{377-80}$ (see online supplemental file 1).

Similarly, while immature features (eg, developmental articulation errors) may persist in the speech of some adults, the sudden emergence of such features, and incongruity with the person's former manner of speaking, age, level of maturity and occupation, suggests an FND. ${ }^{58}$ Such immature speech is often characterised by a combination of prosodic, voice and articulatory alterations such as elevated pitch, exaggerated inflectional patterns and common developmental errors (eg, th/s, w/r); immature speech may be accompanied by infantile gestures and expressions. Functional immature speech may co-occur with functional voice disorders or stuttering and may disappear when the voice or fluency symptoms have resolved with intervention. Treatment by the speech and language professional may be directed towards modification of these obvious speech, voice and infantile pragmatic behaviours. However, in view of the possible symbolic implications of these regressive symptoms, in cases where there is clear evidence of relational difficulties or emotional problems, referral for referral for family therapy with an emphasis on close interpersonal relationships or psychodynamic psychotherapy may be appropriatenecessary. 
Functional FAS may resolve spontaneously or during treatment; but there is relatively little information about the best treatment approaches to use when symptoms persist. Of note, FAS may or may not impact on communicative effectiveness. Others have suggested attention to detailed phonetic analysis with traditional speech therapy while recognising comorbid psychological factors, ${ }^{81}$ or strategies routinely used for accent reduction in non-native speakers of English. ${ }^{82}$ In a case described by Lee et $a l,{ }^{79}$, functional FAS resolved with speech and language therapy approaches combined with CBT. Some treatment suggestions for functional FAS and other disorders of language, prosody and accent are offered in the full version (see online supplemental file 1).

\section{Specific symptoms: globus pharyngeus}

Globus pharyngeus is a functional disorder which presents as a recurrent, non-painful but uncomfortable sensation of a lump in the throat, in the absence of dysphagia, odynophagia, gastrooesophageal reflux disease (GORD/GERD) or a histopathologybased oesophageal motility disorder. Globus commonly co-occurs with functional voice disorders.

Symptoms may be persistent or intermittent and are experienced as a sensation of a foreign body in the throat (eg, hair, crumb); a tightening or choking feeling; a lump in the throat; or sensations of throat strain or itch. Globus is more obvious between meals and improves with eating, but there is often a sense of food and/or liquid sticking or passing with difficulty through the oesophagus. Globus is often associated with throat clearing, a sense of mucus build up or dry throat, repeated swallowing, chronic cough or hoarseness and, over time, dysphonia with pharyngolaryngeal tension. ${ }^{33} 83$

Studies have shown links between globus and psychological stress, ${ }^{84} 85$ with many patients reporting exacerbation of their symptoms during periods of high emotional intensity. Although common, psychological and psychiatric disorders may be an outcome rather than a predisposing factor.

Globus must be distinguished from dysphagia, but while the two symptoms do not necessarily co-occur, empirical data suggests that $20 \%$ of patients with functional dysphagia experience globus sensation with swallowing. ${ }^{86}$ Within gastroenterology, globus is defined often using the Rome IV criteria as a diagnosis of exclusion. ${ }^{33} 35$ This is in contrast to the inclusive methods preferred here for diagnosis of functional voice and speech disorders.

There are few adequately controlled treatment trials for globus. Although spontaneous remission may occur with reduction in psychological stress, $75 \%$ are still symptomatic after 3 years. One study suggested that globus symptoms resolved after reassuring diagnostic investigation by an ear, nose, throat physician ${ }^{838788}$; others have cautioned against over investigation. ${ }^{83} 88$

While therapeutic trials of proton-pump inhibitors are sometimes recommended in order to exclude GERD as a cause of globus, it should be noted that in a randomised controlled trial, globus resolved as frequently in patients administered esomeprazole as in those given placebo. ${ }^{89}$ Antidepressants may be helpful, even in the absence of mood symptoms, in reducing oesophageal pain and discomfort. ${ }^{90}$ In one small trial, the SSRI antidepressant paroxetine was found both effective and superior to low dose amitriptyline (a tricyclic antidepressant), which was superior to the proton-pump inhibitor lansoprazole in treatment of refractory globus. ${ }^{91}$

There is good preliminary evidence for the effectiveness of speech and language therapy in treating globus. ${ }^{36} 889293$ These approaches to management are summarised in the full version (see online supplemental file 1).

\section{Specific symptoms: functional dysphagia}

Functional dysphagia is more often oropharyngeal rather than oesophageal since oropharyngeal musculature is under voluntary rather than autonomic control. For both types of dysphagia exclusion of disease is vital, but for oropharyngeal dysphagia identifying positive features is an important part of the diagnosis and explanation when due to a functional disorder. Positive signs include inability to swallow in the absence of drooling or excessive oral secretions, or inability to control anything in the mouth but ability to spit saliva into a cup.

Symptoms of 'globus', a feeling of it being 'hard' to swallow, pain on swallowing, choking sensations and coughing ${ }^{94}$ are often described by patients with functional dysphagia. Patients often adopt avoidance behaviours as an attempt to reduce the perceived risk of choking. Examples include subtly reducing food intake and textures, changing head postures, eating slowly and with raised bodily tension and social avoidance. Fear of choking is common and functional dysphagia may ultimately lead to unintended weight loss, social withdrawal, anxiety, panic and depression. ${ }^{8695} 96$ The impacts on quality of life are not dissimilar to those experienced by patients suffering dysphagia in association with head and neck cancer. ${ }^{97} 98$

Functional oesophageal dysphagia can be diagnosed using Rome IV criteria, which unlike other disorders in this paper, are based on exclusion of disease rather than positive clinical features of functional disorder, with diagnostic criteria requiring that the following symptoms are present for at least 3 months, with onset 6 months before diagnosis: (1) a sense of solid or liquid food sticking, lodging, or passing abnormally through the oesophagus: (2) an absence of mechanical obstruction, GERD or oesophageal motility disorder causing these symptoms. ${ }^{99}$ Such patients require varying levels of investigation, the details of which are outside the scope of this article.

In some cases functional dysphagia is an isolated symptom, with muscle tension or laryngeal hypersensitivity ${ }^{100}$; in other cases dysphagia may be present as one of a range of functional motor symptoms, for example, in stroke-like presentations; or may be associated with significant phagophobia or psychiatric symptoms. Functional symptoms elsewhere in the gastrointestinal tract, such as cyclical vomiting, may impact on food intake goals.

There have been no randomised controlled trials for treatments specifically targeted at functional dysphagia as opposed to globus. Antidepressants are sometimes used on the basis of evidence of benefit in overlapping disorders causing oesophageal discomfort. ${ }^{90}$

An overview of educational, behavioural and psychological strategies that may be used by speech and language professionals in the management of functional dysphagia are summarised in the full version (see online supplemental file 1). Of note, a recent trial of Cognitive Behaviour-Enhanced Swallowing Therapy in patients recovering from head and neck cancer had promising outcomes; a similar approach may be beneficial in treatment of functional dysphagia. $^{98}$

\section{Specific symptoms:cough and vocal cord dysfunction (laryngeal hypersensitivity syndrome)}

The group suggests that conceptualising laryngeal hypersensitivity syndrome as a functional disorder is appropriate. Chronic cough and vocal cord dysfunction (also known as paradoxical vocal fold motion and inducible laryngeal obstruction) can be considered manifestations of laryngeal hypersensitivity syndrome. Symptoms can occur in the absence of a known cause or persists despite thorough medical 
management. Cough and vocal cord dysfunction persist as a result of reversible changes in function or aberrant involuntary learnt behaviours, rather than primarily due to ongoing disease or damage, but not necessarily in the presence or as a result of significant psychological distress. Importantly, it is possible to have laryngeal hypersensitivity syndrome without meeting criteria for DSM-5 somatic symptom disorder (in which disproportionate time, energy, thoughts, anxious feelings and behaviours persist in relation to the seriousness of the symptoms), which is the way the American College of Chest Physicians have framed conditions previously described as psychogenic cough. ${ }^{101} 102$

It seems likely that the term psychogenic cough has been used inappropriately for a range of types of refractory cough. Idiopathic cough, ${ }^{103}$ medically unexplained cough, ${ }^{10}{ }^{104}$ chronic refractory cough, ${ }^{105}$ neurogenic cough or laryngeal/cough hypersensitivity syndrome, ${ }^{106}$ all refer to cough of unknown aetiology that persists despite medical treatment. Psychiatric comorbidity is far from universal and often secondary rather than causal. ${ }^{103} 107$

Referral should follow respiratory assessment by a physician, which should usually include investigations including spirometry. This group recognises two patterns of dysfunctional cough: (1) persistent habitual cough, and (2) cough which occurs intermittently in a 'hypersensitive' pattern but without objective evidence of airway hypersensitivity, in response to salient stimuli as part of a conditioned response, and with or without perceived panic or autonomic arousal. Respiratory exposure chamber testing may be indicated in some persistent cases. In most cases the diagnosis should be clearly established prior to referral for speech therapy. However, in those cases where patients may self-refer, they should be encouraged to seek formal assessment by a respiratory physician.

The assessment process can help the patient to understand the nature of their disorder, to recognise the key triggers that stimulate their urge to cough and then, how they respond behaviourally to those triggers. Strategies and behavioural guidelines for treatment, as recommended by a speech and language professionals, physiotherapists and respiratory physicians specialising in this area are summarised in the full version (see online supplemental file 1). ${ }^{108-110}$

\section{CONCLUSION}

Functional communication, swallowing and cough symptoms are common, and may be effectively treated with a range of techniques that already form part of the considerable expertise of speech and language professionals.

It is intended that these recommendations help speech and language professionals who work in a variety of settings to feel better able to approach the assessment and treatment of functional disorders with confidence and good outcomes, including as part of a multidisciplinary team treating patients with a range of functional neurological symptoms.

We note as a limitation the dominance of a small number of countries in the authorship, and potential for bias related to the interests of included authors. Future work might helpfully take a more widely international approach to identify key research priorities.

We hope that, by fostering interest into functional disorders as a key part of the work of speech and language professionals, our recommendations might stimulate research towards developing more evidence-based treatments for these disorders.

\section{Author affiliations}

${ }^{1}$ Speech Pathology, Flinders University, Adelaide, South Australia, Australia

${ }^{2}$ University of Technology Sydney, Sydney, New South Wales, Australia

${ }^{3}$ South Warwickshire NHS Foundation Trust, Warwick, UK

${ }^{4}$ Department of Speech \& Language Therapy, Great Ormond Street Hospital for Children NHS Foundation Trust, London, UK

${ }^{5}$ Division of Psychology and Language Sciences, University College London, London, UK

${ }^{6}$ Department of Psychiatry and Psychotherapy, University Hospital Bonn, Bonn, Nordrhein-Westfalen, Germany

${ }^{7}$ National Hospital for Neurology and Neurosurgery, London, UK

${ }^{8}$ Department of Neurology, Mayo Clinic, Rochester, Minnesota, USA

${ }^{9}$ Speech and Language Therapy, Kent Community Health NHS Foundation Trust, Ashford, UK

${ }^{10}$ Department of Clinical Neurosciences, Royal Infirmary of Edinburgh, Edinburgh, UK

${ }^{11}$ Massachusetts General Hospital, Boston, Massachusetts, USA

${ }^{12}$ Lewisham and Greenwich NHS Trust, London, UK

${ }^{13}$ Speech Language Sciences, Newcastle University, Newcastle upon Tyne, UK

${ }^{14}$ University of Liverpool, Liverpool, UK

${ }^{15}$ Speech Pathology Division, Naval Medical Center San Diego, San Diego, California, USA

${ }^{16}$ Department of Communication Sciences and Disorders, The University of Utah, Salt Lake City, Utah, USA

${ }^{17}$ Division of Otolaryngology - Head and Neck Surgery (Adjunct), The University of Utah, Salt Lake City, Utah, USA

${ }^{18}$ North Bristol NHS Trust, Westbury on Trym, UK

${ }^{19}$ Neurology, Mayo Clinic, Rochester, Minnesota, USA

${ }^{20}$ Speech Pathology and Neurology, Mayo Clinic College of Medicine and Science,

Rochester, Minnesota, USA

${ }^{21}$ School of Communication Sciences and Disorders, Institute for Intelligent Systems, The University of Memphis, Memphis, Tennessee, USA

${ }^{22}$ Speech Pathology, John Hunter Hospital, Newcastle, New South Wales, Australia

${ }^{23}$ Centre for Healthy Lungs, Hunter Medical Research Institute; School of Medicine and Public Health, The University of Newcastle, Newcastle, New South Wales, Australia

${ }^{24}$ Centre for Clinical Brain Sciences, The University of Edinburgh, Edinburgh, UK

Twitter Lesley Cavalli @CavalliLesley, Alan Carson @alancarson15, Jon Stone @ jonstoneneuro and Laura McWhirter @lauramcw

Contributors LM, JS and AC developed the concept of the paper and together with JB defined the scope and assembled a group of expert coauthors. All authors contributed materially and substantially to a detailed online survey establishing the content of the manuscript, attended a zoom meeting for discussion of issues arising, and contributed to multiple subsequent rounds of comments and revision as per the methods described in the paper. LM coordinated this process. JB wrote the initial draft, which was sequentially revised by LM and JB as per this process. JS revised the long version to produce an abbreviated version to submit for print publication.

Funding The authors have not declared a specific grant for this research from any funding agency in the public, commercial or not-for-profit sectors.

Competing interests LM is funded by a University of Edinburgh Clinical Research Fellowship funded philanthropically by Baillie Gifford. LM provides independent medical testimony in court cases regarding patients with functional disorders. AC is a director of a limited personal services company that provides independent medical testimony in Court Cases on a range of neuropsychiatric topics on a $50 \%$ pursuer $50 \%$ defender basis, is an associate editor of the Journal of Neurology Neurosurgery and Psychiatry, and is the treasurer of the International Functional Neurological Disorder Society. JS reports personal fees from UptoDate, outside the submitted work, runs a self help website for patients with functional neurological symptoms (www.neurosymptoms.org) which is free and has no advertising, provides independent medical testimony in personal injury and negligence cases regarding patients with functional disorders, and is secretary of the International Functional Neurological Disorder Society. JS is a Chief Scientists Office NHS Research Scotland Career Researcher

\section{Patient consent for publication Not required.}

Provenance and peer review Not commissioned; externally peer reviewed.

Supplemental material This content has been supplied by the author(s). It has not been vetted by BMJ Publishing Group Limited (BMJ) and may not have been peer-reviewed. Any opinions or recommendations discussed are solely those of the author(s) and are not endorsed by BMJ. BMJ disclaims all liability and responsibility arising from any reliance placed on the content. Where the content includes any translated material, BMJ does not warrant the accuracy and reliability of the translations (including but not limited to local regulations, clinical guidelines, terminology, drug names and drug dosages), and is not responsible for any error and/or omissions arising from translation and adaptation or otherwise. 


\section{ORCID iDs}

Rene Utianski http://orcid.org/0000-0001-9519-1302

Jon Stone http://orcid.org/0000-0001-9829-8092

Laura McWhirter http://orcid.org/0000-0001-9839-6549

\section{REFERENCES}

1 Espay AJ, Aybek S, Carson A, et al. Current concepts in diagnosis and treatment of functional neurological disorders. JAMA Neurol 2018;75:1132-41.

2 Stone J, Carson A, Duncan R, et al. Who is referred to neurology clinics?--the diagnoses made in 3781 new patients. Clin Neurol Neurosurg 2010;112:747-51.

3 Heyman I. Mind the gap: integrating physical and mental healthcare for children with functional symptoms. Arch Dis Child 2019;104:1127-8.

4 Barnett C, Mitchell C, Tyson S. The management of patients with functional stroke: speech and language therapists' views and experiences. Disabil Rehabil 2021.

5 Duffy JR. Functional speech disorders: clinical manifestations, diagnosis, and management. In: Hallett M, Stone J, Carson A, eds. Functional Neurologic Disorders, Volume 139 of the Handbook of Clinical Neurology series, 2016: 379-88.

6 Nicholson C, Edwards MJ, Carson AJ, et al. Occupational therapy consensus recommendations for functional neurological disorder. J Neurol Neurosurg Psychiatry 2020:91:1037-45.

7 Nielsen G, Stone J, Matthews A, et al. Physiotherapy for functional motor disorders: a consensus recommendation. J Neurol Neurosurg Psychiatry 2015;86:1113-9.

8 Baker J, Ben-Tovim DI, Butcher A, et al. Development of a modified diagnostic classification system for voice disorders with inter-rater reliability study. Logoped Phoniatr Vocol 2007;32:99-112

9 Barnett C, Armes J, Smith C, Speech SC. Speech, language and swallowing impairments in functional neurological disorder: a scoping review. Int I Lang Commun Disord 2019;54:309-20.

10 Short J, Harding S. A systematic exploration of the terminology used in the diagnosis and treatment of oropharyngeal dysphagia (swallowing difficulty) in the absence of a clear medical explanation. In: RCSLT Conference. Nottingham 2019.

11 Baker J. The role of psychogenic and psychosocial factors in the development of functional voice disorders. Int J Speech Lang Pathol 2008;10:210-30.

12 Baker J, Ben-Tovim D, Butcher A, et al. Psychosocial risk factors which may differentiate between women with functional voice disorder, organic voice disorder and a control group. Int J Speech Lang Pathol 2013;15:547-63.

13 Butcher P, Elias A, Cavalli L. Understanding and treating psychogenic voice disorder: A CBT framework. New York: Chichester and Wiley, 2007.

14 Deary V, Miller T. Reconsidering the role of psychosocial factors in functional dysphonia. Curr Opin Otolaryngol Head Neck Surg 2011:19:150-4.

15 O'Hara J, Miller T, Carding P, et al. Relationship between fatigue, perfectionism, and functional dysphonia. Otolaryngol Head Neck Surg 2011;144:921-6.

16 Roy N, Bless DM. Personality traits and psychological factors in voice pathology: a foundation for future research. J Speech, Lang Hear Res 2000;43:737-48.

17 Roy N, Bless DM. Toward a theory of the dispositional bases of functional dysphonia and vocal nodules: Exploring the role of personality and emotional adjustment. In: The handbook of voice quality measurement, 2000: 461-80. https://www. researchgate.net/profile/Nelson_Roy/publication/313695030_Toward_a_Theory_ of the Dispositional_Bases of Functional_Dysphonia and Vocal_Nodules Exploring_the_Role_of_Personality_and_Emotional_Adjustment/links/58a31 cb9 92851 cb987733ebb/Toward-a-T

18 van Mersbergen M, Patrick C, Glaze L. Functional dysphonia during mental imagery: testing the trait theory of voice disorders. I Speech Lang Hear Res 2008:51:1405-23. doi:10.1093/brain/aws129

19 Ludwig L, Pasman JA, Nicholson T, et al. Stressful life events and maltreatment in conversion (functional neurological) disorder: systematic review and meta-analysis of case-control studies. Lancet Psychiatry 2018;5:307-20.

20 Edwards MJ. Neurobiologic theories of functional neurologic disorders. In: Hallett M, Stone J, Carson A, eds. Functional neurologic disorders, volume 139 of the Handbook of clinical neurology series, 2016: 131-7.

21 Edwards MJ, Adams RA, Brown H, et al. A Bayesian account of 'hysteria'. Brain 2012:135:3495-512

22 Pareés I, Kojovic M, Pires C, et al. Physical precipitating factors in functional movement disorders. J Neurol Sci 2014:338:174-7.

23 Hallett M, Stone J, Carson A. Volume 139 of the Handbook of Clinical Neurology series. Amsterdam: Elsevier, 2016.

24 Haggard P. Sense of agency in the human brain. Nat Rev Neurosci 2017;18:196-207.

25 Talmon M. Single-session therapy: maximizing the effect of the first (and often only) therapeutic encounter. Jossey-Bass, 1990. https://psycnet.apa.org/record/199098311-000

26 Baker J. Psychosocial perspectives on the management of voice disorders. Compton Publishing: Oxford:, 2017

27 Lehn A, Gelauff J, Hoeritzauer I, et al. Functional neurological disorders: mechanisms and treatment. J Neurol 2016;263:611-20.

28 Stone J. Functional neurological disorders: the neurological assessment as treatment. Pract Neurol 2016;16:7-17.
29 Adams C, Anderson J, Madva EN, et al. You've made the diagnosis of functional neurological disorder: now what? Pract Neurol 2018:18:323-30.

30 Gilmour GS, Nielsen G, Teodoro T, et al. Management of functional neurological disorder. J Neurol 2020:267:2164-72.

31 LaFaver K. Treatment of functional movement disorders. Neurol Clin 2020;38:469-80

32 Stone J, Edwards M. Trick or treat? showing patients with functional (psychogenic) motor symptoms their physical signs. Neurology 2012;79:282-4.

33 In:Baumann A, Katz PO. Functional disorders of swallowing. Handb Clin Neurol 2016;139:483-8

34 Duffy J. Motor speech disorders. 4th ed. St Louis: Elsevier, 2020.

35 Galmiche JP, Clouse RE, Bálint A, et al. Functional esophageal disorders. Gastroenterology 2006;130:1459-65 https://www.sciencedirect.com/science/article/ pii/S0016508506005075

36 Harvey PR, Theron BT, Trudgill NJ. Managing a patient with globus pharyngeus. Frontline Gastroenterol 2018;9:208.1-12.

37 McWhirter L, Miller N, Campbell C, et al. Understanding foreign accent syndrome. J Neurol Neurosurg Psychiatry 2019;90:1265-9.

38 Roth CR, Cornis-Pop M, Beach WA. Examination of validity in spoken language evaluations: adult onset stuttering following mild traumatic brain injury. NeuroRehabilitation 2015;36:415-26.

39 Titze IR, Verdolini Abbott K. Vocology The Science and Practice of Voice Habilitation. Salt Lake City: National Center for Voice and Speech, 2012

40 EML Y, Verdolini K, Chow LPY. Electromyographic study of motor learning for a voice production task. J Speech, Lang Hear Res 2005;48:1254-68.

41 Squire LR. Mechanisms of memory. University of California Press, 1986. http:// science.sciencemag.org/

42 Boone D. The voice and voice therapy. New Jersey: Prentice-Hall, 1977.

43 Baker J. Psychogenic dysphonia: peeling back the layers. J Voice 1998;12:527-35.

44 Goldstein LH, Robinson EJ, Mellers JDC, et al. Cognitive behavioural therapy for adults with dissociative seizures (codes): a pragmatic, multicentre, randomised controlled trial. Lancet Psychiatry 2020;7:491-505.

45 Richardson M, Isbister G, Nicholson B. A novel treatment protocol (nocebo hypothesis cognitive behavioural therapy; NH-CBT) for functional neurological symptom disorder/conversion disorder: a retrospective consecutive case series. Behav Cogn Psychother 2018;46:497-503.

46 Butcher P, Elias A. Cognitive-Behavioural therapy with dysphonic patients: an exploratory investigation. Coll Speech Ther Bull 1983;377:1-3 https://scholar.google. com/scholar?hl=en\&as sdt=0\%2C5\&q=Butcher $\% 2 C+P . \% 2 C+\% 26+$ Elias $\% 2 C+$ A.+\%281983\%29.+Cognitive-behavioural+therapy+with+dysphonic+patients\% $3 \mathrm{~A}+$ An+exploratory+investigation.+The+College+of+Speech+Therapists+ Bulletin\%28377\%29\%2C+1-3.+\&btnG=

47 Carding P, Deary V, Miller T. Cognitive behavioural therapy in the treatment of functional dysphonia in the United Kingdom. In: Yiu E, ed. International perspectives on voice disorders. UK: Multilingual Matters / Channel View Publications, 2013: 133-48.

48 Deary V, McColl E, Carding P, et al. A psychosocial intervention for the management of functional dysphonia: complex intervention development and pilot randomised trial. Pilot Feasibility Stud 2018;4.

49 Miller T, Deary V, Patterson J. Improving access to psychological therapies in voice disorders: a cognitive behavioural therapy model. Curr Opin Otolaryngol Head Neck Surg 2014;22:201-5.

50 Gutkin M, McLean L, Brown R, et al. Systematic review of psychotherapy for adults with functional neurological disorder. J Neurol Neurosurg Psychiatry 2021:92:36-44.

51 Baker J. The therapeutic relationship once established, need never be broken. Int $J$ Speech Lang Pathol 2010;12:309-12.

52 Roy $\mathrm{N}$, Dietrich M, Blomgren M, et al. Exploring the neural bases of primary muscle tension dysphonia: a case study using functional magnetic resonance imaging. J Voice 2019:33:183-94.

53 Spengler FB, Becker B, Kendrick KM, et al. Emotional dysregulation in psychogenic voice loss. Psychother Psychosom 2017:86:121-3.

54 Baker J. Functional voice disorders: clinical presentations and differential diagnosis. In: Hallett M, Stone J, Carson A, eds. Functional neurologic disorders, volume 139 of the Handbook of clinical neurology series. Amsterdam: Elsevier, 2016: 389-406

55 Verdolini K, Rosen C, Branski R. Classification Manual for Voice Disorders-I. New Jersey: Laurence Erlbaum Associates, 2006

56 Dietrich M, Verdolini Abbott K. Psychobiological stress reactivity and personality in persons with high and low stressor-induced extralaryngeal reactivity. I Speech Lang Hear Res 2014:57:2076-89.

57 Roy N, Bless DM, Heisey D. Personality and voice disorders: a multitrait-multidisorder analysis. Journal of Voice 2000;14:521-48.

58 Aronson A, Bless DM. Clinical voice disorders. 4th ed. New York: Thieme, 2009.

59 Roy N. Assessment and treatment of musculoskeletal tension in hyperfunctional voice disorders. Int I Speech Lang Pathol 2008;10:195-209.

60 Kollbrunner J, Seifert E. Encouragement to increase the use of psychosocial skills in the diagnosis and therapy of patients with functional dysphonia. Journal of Voice 2017;31:132.e1-132.e7 
61 Kiese-Himmel C. Klinisch-psychologische Bausteine in der Diagnostik funktioneller Dysphonien - eine Übersicht. Laryngorhinootologie 2015;94:156-62.

62 Behrendt S. Die psychogene Aphonie auf dem Hintergrund psychotherapeutischer Modelle und Erfahrungen. Sprache Stimme Gehör 2002;26:9-13.

63 Ruotsalainen J, Sellman J, Lehto L. Systematic review of the treatment of functional dysphonia and prevention of voice disorders. Otolaryngol. - Head Neck Surg 2008;138:557-65.

64 Speyer R. Effects of voice therapy: a systematic review. Journal of Voice 2008;22:565-80.

65 Carding P, Bos-Clark M, Fu S, et al. Evaluating the efficacy of voice therapy for functional, organic and neurological voice disorders. Clin Otolaryngol 2017:42:201-17.

66 Griffith MM. Identifying speech-language pathologists' current perceptions and practice patterns, 2015. Available: https://encompass.eku.edu/etd [Accessed 19 Jan 2021].

67 Baumgartner J, Duffy JR. Psychogenic stuttering in adults with and without neurologic disease. J Med Speech Lang Pathol 1997;5:75-95 https://www. researchgate.net/profile/Joseph_Duffy/publication/279897923_Psychogenic stuttering_in_adults_with_and_without_neurologic_disease/links/565493ca08ae afc2aabbe37d.pdf

68 Deal JL. Sudden onset of stuttering: a case report. J Speech Hear Disord 1982;47:301-4.

69 Binder LM, Spector J, Youngjohn JR. Psychogenic stuttering and other acquired nonorganic speech and language abnormalities. Archives of Clinical Neuropsychology 2012;27:557-68.

70 Helm-Estabrooks N, Hotz G. Sudden Onset of "Stuttering" in an Adult: Neurogenic or Psychogenic? Semin Speech Lang 1998;19:23-9.

71 Connery A, McCurtin A, Robinson K. The lived experience of stuttering: a synthesis of qualitative studies with implications for rehabilitation. Disabil Rehabil 2020;42:2232-42.

72 Scheurich JA, Beidel DC, Vanryckeghem M. Exposure therapy for social anxiety disorder in people who stutter: an exploratory multiple baseline design. J Fluency Disord 2019:59:21-32.

73 Beilby J. Psychosocial impact of living with a stuttering disorder: knowing is not enough. Semin Speech Lang 2014;35:132-43.

74 Baizabal-Carvallo JF, Jankovic J. Speech and voice disorders in patients with psychogenic movement disorders. J Neurol 2015;262:2420-4.

75 Chung DS, Wettroth C, Hallett M, et al. Functional speech and voice disorders: case series and literature review. Mov Disord Clin Pract 2018:5:312-6.

76 Jones A, Smakowski A, O'Connell N, et al. Functional stroke symptoms: a prospective observational case series. J Psychosom Res 2020;132:109972.

77 Keulen S, Verhoeven J, De Page L, et al. Psychogenic foreign accent syndrome: a new case. Front Hum Neurosci 2016;10:143.

78 Keulen S, Verhoeven J, Bastiaanse R, et al. Perceptual accent rating and attribution in psychogenic FAS: some further evidence challenging whitaker's operational definition. Front Hum Neurosci 2016;10:1-14.

79 Lee 0, Ludwig L, Davenport R, et al. Functional foreign accent syndrome. Pract Neurol 2016:16:409-11

80 Romö N, Miller N, Cardoso A. Segmental diagnostics of neurogenic and functional foreign accent syndrome. J Neurolinguistics 2021;58:100983.

81 Haley KL, Roth HL, Helm-Estabrooks N, et al. Foreign accent syndrome due to conversion disorder: Phonetic analyses and clinical course. J Neurolinguistics 2010;23:28-43.

82 Sikorski LD. Foreign accents: suggested competencies for improving communicative pronunciation. Semin Speech Lang 2005;26:126-30.

83 Karkos PD, Wilson JA. The diagnosis and management of globus pharyngeus: our perspective from the United Kingdom. Curr Opin Otolaryngol Head Neck Surg 2008; 16:521-4.

84 Deary IJ, Wilson JA, Kelly SW. Globus pharyngis, personality, and psychological distress in the general population. Psychosomatics 1995;36:570-7.
85 Harris MB, Deary IJ, Wilson JA. Life events and difficulties in relation to the onset of globus pharyngis. J Psychosom Res 1996;40:603-15.

86 Elias A. Our voice and neuro caseloads - making the links. NHS, 2019.

87 Järvenpää P, Arkkila P, Aaltonen L-M. Globus pharyngeus: a review of etiology, diagnostics, and treatment. Eur Arch Otorhinolaryngol 2018;275:1945-53.

88 Lee BE, Kim GH. Globus pharyngeus: a review of its etiology, diagnosis and treatment. World J Gastroenterol 2012;18:2462-71.

89 Noordzij JP, Khidr A, Evans BA, et al. Evaluation of omeprazole in the treatment of reflux laryngitis: a prospective, placebo-controlled, randomized, double-blind study. Laryngoscope 2001;111:2147-51.

90 Weijenborg PW, de Schepper HS, Smout AJPM, et al. Effects of antidepressants in patients with functional esophageal disorders or gastroesophageal reflux disease: a systematic review. Clin Gastroenterol Hepatol 2015;13:251-9.

91 Chen D-yun, Jia L, Gu X, et al. Comparison of paroxetine and amitriptyline in the treatment of refractory globus pharyngeus. Digestive and Liver Disease 2016;48:1012-7

92 Khalil HS, Reddy VM, Bos-Clark M, et al. Speech therapy in the treatment of globus pharyngeus: how we do it. Clin Otolaryngol 2011;36:388-92.

93 Wareing M, Elias A, Mitchell D. Management of globus sensation by the speech therapist. Logoped Phoniatr Vocol 1997;22:39-42.

94 Kang CH, Zhang N, Lott DG. Muscle tension dysphagia: contributing factors and treatment efficacy. Ann Otol Rhinol Laryngol 2020;000348942096633:0003489420 96633.

95 Verdonschot RJCG, Baijens LWJ, Vanbelle S, et al. Affective symptoms in patients with oropharyngeal dysphagia: a systematic review. J Psychosom Res 2017;97:102-10.

96 Bülow M. Psychogenic dysphagia. In: Principles of Deglutition: A Multidisciplinary Text for Swallowing and its Disorders. Springer New York 2013:771-6.

97 Patterson JM. Psychological interventions for the head and neck cancer population who are experiencing dysphagia. Perspect ASHA SIGs 2019:4:1049-54.

98 Patterson JM, Fay M, Exley C, McColl E, et al. Feasibility and acceptability of combining cognitive behavioural therapy techniques with swallowing therapy in head and neck cancer dysphagia. BMC Cancer 2018;18:1-11.

99 Aziz Q, Fass R, Gyawali CP, et al. Esophageal disorders. Gastroenterology 2016:150:1368-79.

100 Kang CH, Hentz JG, Lott DG. Muscle tension dysphagia: symptomology and theoretical framework. Otolaryngol Head Neck Surg 2016;155:837-42.

101 Vertigan AE. Somatic cough syndrome or psychogenic cough-what is the difference? J Thorac Dis 2017:9:831-8.

102 Vertigan AE, Murad MH, Pringsheim T, et al. Somatic cough syndrome (previously referred to as psychogenic cough) and tic cough (previously referred to as habit cough) in adults and children. Chest 2015;148:24-31.

103 McGarvey LPA, Carton C, Gamble LA, et al. Prevalence of psychomorbidity among patients with chronic cough. Cough 2006:2:4-6.

104 Gibson P, Wang G, McGarvey L. Treatment of unexplained chronic cough chest guideline and expert panel report. Chest 2016;149:27-44.

105 Gibson PG, Vertigan AE. Management of chronic refractory cough. BMJ 2015;351:h5590.

106 Song WJ, Morice AH. Cough hypersensitivity syndrome: a few more steps forward. Allergy Asthma Immunol Res 2017:9:394-402.

107 Dicpinigaitis PV, Tso R, Banauch G. Prevalence of depressive symptoms among patients with chronic cough. Chest 2006;130:1839-43.

108 Chamberlain Mitchell SAF, Ellis J, Ludlow S, et al. Non-Pharmacological interventions for chronic cough: the past, present and future. Pulm Pharmacol The 2019;56:29-38

109 Mathur A, Liu-Shiu-Cheong PSK, Currie GP. The management of chronic cough. QJM 2019:112:651-6.

110 Vertigan AE, Theodoros DG, Gibson PG, et al. Efficacy of speech pathology management for chronic cough: a randomised placebo controlled trial of treatment efficacy. Thorax 2006;61:1065-9. 